\title{
EPAS1, a Dexamethasone-Inducible Gene in Osteoblasts, Inhibits Osteoblastic Differentiation
}

\author{
Nobuhiro Ijichi ${ }^{1}$, Kazuhiro Ikeda ${ }^{1}$, Masayo Fujita ${ }^{2}$, Takahiko Usui ${ }^{2,3}$, Tomohiko Urano ${ }^{1,2,3}$, \\ Kotaro Azuma $^{2}$, Yasuyoshi Ouchi ${ }^{2}$, Kuniko Horie-Inoue ${ }^{1}$ and Satoshi Inoue ${ }^{*}, 1,2,3$ \\ ${ }^{I}$ Division of Gene Regulation and Signal Transduction, Research Center for Genomic Medicine, Saitama Medical \\ University, Saitama, Japan
}

Departments of ${ }^{2}$ Geriatric Medicine and ${ }^{3}$ Anti-Aging Medicine, Graduate School of Medicine, The University of Tokyo, Tokyo, Japan

\begin{abstract}
Glucocorticoid-induced osteoporosis is a clinical problem in patients under chronic steroid therapy. To delineate the action of glucocorticoids on osteoblasts, we performed microarray analysis using rat primary osteoblasts and identified several glucocorticoid target genes. We validated the dexamethasone-induced upregulation of CCAAT/ enhancer-binding protein delta $(\mathrm{C} / \mathrm{EBP} \delta)$, endothelial PAS-domain protein 1 (EPAS1), matrix Gla protein (MGP), and nerve growth factor inducible-B (NGFI-B) expression by quantitative real time-polymerase chain reaction (qPCR). EPAS1 overexpression inhibited, whereas dominant-negative EPAS1 overexpression enhanced the upregulation of osteoblastic marker genes and the mineralization in ST2 mesenchymal cells under the simulated osteoblastogenesis conditions. These results suggest that glucocorticoids could inhibit osteoblastic differentiation by regulating its target genes, as exemplified by EPAS1.
\end{abstract}

\section{INTRODUCTION}

Glucocorticoids (GC), which are widely used as antiinflammatory and immunosuppressive agents, have serious side effects on bones, causing bone loss and osteoporosis [1, 2]. GC-induced bone loss has also been reported in mice [3] and rat [4], suggesting that GC exerts common bone-tissue effects among mammalian species. Furthermore, GC is known to play a stimulatory role in bone resorption; thus, these steroids would also have detrimental effects on osteoblast proliferation, differentiation, and physiological function [1]. GC may impair osteoblastic metabolism by inhibiting collagen synthesis and the functions of osteoblastogenesis-related genes, including core binding factor $\alpha 1$ (Cbfa1), insulin-like growth factor (IGF)-1, and transforming growth factor (TGF)- $\beta$ [5-7]. GC also induces apoptosis of osteoblasts $[3,8]$.

The intensity of the GC effects depends on the growth and differentiation stages of osteoblasts $[9,10]$ as well as the concentration of glucocorticoid [11]. For example, cortisol has been shown to prevent the terminal differentiation of primary osteoblasts during osteoblastic differentiation and mineralization [10]. Dexamethasone (Dex) inhibited cell cycle progression and mineralization in MC3T3-E1 osteoblastic cells in postconfluent cultures, but not in preconfluent cultures [9].

*Address correspondence to this author at the Department of Geriatric Medicine, Graduate School of Medicine, The University of Tokyo, 7-3-1 Hongo, Bunkyo-ku, Tokyo 113-8655, Japan; Tel: +81-3-5800-8652; Fax: +81-42-984-4541; E-mail: INOUE-GER@h.u-tokyo.ac.jp
$\mathrm{GC}$ regulates the transcription of its target genes and exerts various biological functions by binding to the glucocorticoid receptor (GR), one of the classical steroid hormone nuclear receptors. GR expression has also been confirmed in osteoblasts, where GC regulates the expression of several target genes, including bone sialoprotein [12], glutamine synthase [13], and dickkopf-1 [14]. However, the identification of additional target genes is essential to understand the precise mechanism underlying $\mathrm{GC}$-induced osteoporosis. In the present study, we examined GC-regulated gene expression in rat primary osteoblasts at different differentiation stages and identified novel GC target genes that contribute to osteoblastic differentiation in differentiation stage-specific and GC dose-dependent manners.

\section{MATERIALS AND METHODOLOGY}

\section{Cell Culture}

Rat primary osteoblasts were isolated from the calvaria of 5-day-old neonatal rats as described previously [15]. Cells obtained from the second passage were used for experiments. All animal experiments were approved by the Institutional Animal Care and Use Committee. ST2 cells were obtained from American Type Culture Collection (Manassas, VA), and maintained in alpha-minimum essential medium ( $\alpha$-MEM) supplemented with $10 \%$ fetal bovine serum (FBS), 50 units $/ \mathrm{ml}$ penicillin, and $50 \mu \mathrm{g} / \mathrm{ml}$ streptomycin. 


\section{Induction of Osteoblastic Differentiation}

Rat primary osteoblasts were maintained in culture medium containing $\alpha$-MEM (including $50 \mu \mathrm{g} / \mathrm{ml}$ ascorbic acid) with $10 \%$ FBS and antibiotics. After 1 week of culture, when a confluent cell layer was obtained, the culture medium was replaced with osteoblast differentiation medium containing $\alpha$-MEM with $50 \mathrm{nM} \beta$-glycerophosphate, and the cells were then cultured for another 1 or 3 weeks (hereafter, mentioned as 2 and 4 weeks of culture, respectively). Increased mRNA levels of the differentiation markers alkaline phosphatase (ALP) and osteocalcin were confirmed by real-time polymerase chain reaction (PCR) during the 4week differentiation course; this was consistent with previous reports [1]. Thus, the model used in the present study reflects the differentiation process of osteoblastic cells. The culture medium was changed $24 \mathrm{~h}$ before every analysis. ST2 cells were grown to confluency, and differentiation was induced at $1 \mathrm{~d}$ postconfluence (day 0 ) by replacing the culture medium with the differentiation medium, i.e., medium containing $20 \mathrm{ng} / \mathrm{ml}$ bone morphogenetic protein 9 (BMP-9) (R\&D systems, Minneapolis, MN). The differentiation medium was also changed every $3 \mathrm{~d}$, and the cells were cultured up to $9 \mathrm{~d}$ after differentiation was induced (day 9).

\section{Microarray Analysis}

At 2 and 4 weeks of culture, the cells were incubated with $10 \mathrm{nM}$ Dex or a vehicle for 2 or $6 \mathrm{~h}$, and then, total RNA was extracted from the cells using a ToTALLY RNA Kit (Ambion, Austin, TX). cDNA was synthesized from $5 \mu \mathrm{g}$ of total RNA using a T7 promoter primer and amplified to generate cyanine 3- or cyanine 5-labeled cRNA using the Fluorescent Linear Amplification Kit (Agilent Technology, Palo Alto, CA). cDNA derived from Dex-treated primary osteoblasts and vehicle-treated primary osteoblasts were labeled with cyanine 5 and cyanine 3 , respectively. Hybridization solution was prepared, subjected to the rat oligomicroarray (Agilent Technology), and hybridized at $60^{\circ} \mathrm{C}$ for $17 \mathrm{~h}$. After hybridization, the microarray was scanned with the GenePix 4000B scanner (Molecular Devices, Union City,
CA). The raw data obtained from the scanned array images were analyzed with the Genespring 6.1 software (Agilent Technology). In the present study, if the expression of a gene increased by greater than 2.5 fold at either 2 or $6 \mathrm{~h}$ after Dex treatment compared with the vehicle treatment, it was considered to be upregulated.

\section{Plasmid Construction}

Human endothelial PAS-domain protein 1 (EPAS1) cDNA (EPAS1 amino acids 2-870) or its dominant-negative mutant (EPAS1 amino acids 2-485) were N-terminally tagged with Flag and HA, and subcloned into the pCXN2 vector (pCXN2-FLAG-HA-EPAS1 and pCXN2-FLAG-HADN-EPAS1, respectively).

\section{Quantitative Real Time-PCR}

Total RNA was extracted from rat primary osteoblasts or ST2 cells at the indicated times during the period of osteoblastic induction. Quantitative real time-PCR (qPCR) analysis was performed as described previously [16]. The sequences of the PCR primers for glyceraldehyde-3-phosphate dehydrogenase (GAPDH), ALP, osteocalcin, CCAAT/ enhancer-binding protein delta $(\mathrm{C} / \mathrm{EBP} \delta), \mathrm{EPAS} 1$, matrix Gla protein (MGP), and nerve growth factor inducible-B (NGFI-B) for rat and GAPDH, ALP, and osteocalcin for mouse are listed in Table $\mathbf{1 .}$

The expression level of each gene was normalized to the GAPDH expression level. Three independent measurements were performed and the standard error was calculated.

\section{Generation of Stable Cell Lines}

ST2 cells were transfected with pCXN2-FLAG-HAEPAS1, pCXN2-FLAG-HA-DN-EPAS1 or empty pCXN2 plasmid using the Lipofectamine 2000 reagent (Invitrogen, Carlsbad, CA) and neo-resistant clones were isolated by G418 selection $(0.6 \mathrm{mg} / \mathrm{ml})$. Expression levels of FLAGHA-human EPAS1 or FLAG-HA-human DN-EPAS1 mRNA were measured by qPCR using the following

Table 1. Gene-Specific Primers for Quantitative RT-PCR

\begin{tabular}{|c|c|c|c|}
\hline Species & Gene & Forward Primer (5' to 3') & Reverse Primer (5' to 3') \\
\hline \hline Rat & GAPDH & GGCACAGTCAAGGCTGAGAAT & TCGCGCTCCTGGAAGATG \\
\hline Rat & ALP & TGACCACCACTCGGGTGAA & GCATCTCATTGTCCGAGTACCA \\
\hline Rat & Osteocalcin & CCACCGTTTAGGGCATGTGT & CGAGTCCTGGAGAGTAGCCAAA \\
\hline Rat & C/EBP 8 & AACCAGGAGATGCAGCAGAAG & CCACACGCTGATGCAGCTT \\
\hline Rat & EPAS1 & TGTTCAAGATGAGGTCTGCAAAG & GCTTGTTGGACAGGGCTATCA \\
\hline Rat & MGP & CCGCCTACAACCGCTACTTC & CCGTAACAAAGCGACTGTTTCC \\
\hline Rat & NGFI-B & GGCTTTGGTGACTGGATAGACAA & CAGGAACATCAACACCCAAGCT \\
\hline Mouse & GAPDH & GCATGGCCTTCCGTGTTC & TGTCATCATACTTGGCAGGTTTCT \\
\hline Mouse & ALP & CCAATGTAGCCAAGAATGTCATCA & GATTCGGGCAGCGGTTACT-3' \\
\hline Mouse & Osteocalcin & CGGCCCTGAGTCTGACAAA & GCCGGAGTCTGTTCACTACCTT \\
\hline
\end{tabular}


primers: forward, 5'- GACTACAAGGACGATGATGAC AAG-3'; reverse, 5'-GCATAATCAGGAACATCATACGG ATA-3'.

\section{von Kossa Staining}

ST2 cells stably expressing EPAS1 (ST2-EPAS1) or a dominant negative EPAS1mutant (ST2-DN-EPAS1) were cultured in an osteoblast differentiation medium for $30 \mathrm{~d}$; thereafter, von Kossa staining for calcium was performed as described previously [17]. Briefly, fixed cells were incubated with $5 \%$ silver nitrate for $5 \mathrm{~min}$ in daylight. All the staining images were captured and the intensity of staining was quantified using the NIH Image program (developed at the U.S. National Institutes of Health and available on the internet at http://rsb.info.nih.gov/nih-image/). The results were indicated as the mean $\pm \mathrm{SD}$ of the relative intensity of 10 independent areas in each cell culture.

\section{Statistical Analysis}

Differences between the 2 groups were analyzed using the paired Student's $t$ test. A p value less than 0.05 was considered to be significant. All data are presented in the text and figures as the mean $\pm \mathrm{SD}$.

\section{RESULTS}

\section{Microarray Analysis of Rat Primary Osteoblasts Treated with Dex after Osteoblastic Differentiation}

We performed microarray analysis using mRNA obtained from rat primary osteoblasts at 2 and 4 weeks after osteoblastic differentiation, i.e., "early and late differentiation stages," respectively, to identify genes that were upregulated by Dex treatment. Cells at 2 weeks after differentiation were cultured for a week to obtain a confluent cell layer and for another week with $\beta$-glycerophosphate, while cells at 4 weeks were cultured for 2 more weeks with $\beta$ glycerophosphate. Note that the calcification of primary osteoblasts was observed only at a "late differentiation stage." The primary osteoblasts at the early and late differentiation stages were treated with Dex $(10 \mathrm{nM})$ for $2 \mathrm{~h}$ or $6 \mathrm{~h}$, and genes that were upregulated by $>2.5$ fold in response to Dex treatment were defined as GC target genes.

At the early and late differentiation stages, 18 and 50 genes were upregulated by Dex treatment, respectively (Tables 2 and 3). Sixteen genes were upregulated at both stages. Other genes may be induced stage specifically.

Table 2. Up-Regulated Genes by 2-h or 6-h Treatment with Dexamethasone (10 nM) in Rat Primary Osteoblasts Cultured for 2 Weeks in a Condition of Osteoblastic Differentiation Identified by Microarray Analysis ${ }^{\mathrm{a}}$

\begin{tabular}{|c|c|c|c|}
\hline \multirow{2}{*}{$\begin{array}{c}\text { GeneBank } \\
\text { Accession No. }\end{array}$} & \multicolumn{2}{|c|}{ Fold Change $^{\mathrm{b}}$} & \multirow{2}{*}{ Description } \\
\hline & $2 \mathrm{~h}$ & $6 \mathrm{~h}$ & \\
\hline NM_013154 & 6.84 & 5.19 & CCAAT/enhancer binding, protein (C/EBP) delta \\
\hline NM_138826 & 5.06 & 3.79 & Metallothionein \\
\hline BE111806 & 4.00 & 2.50 & RM1 mRNA, partial sequence \\
\hline NM_080906 & 3.98 & 2.25 & HIF-1 responsive RTP801 \\
\hline NM_053536 & 3.93 & 3.20 & Kruppel-like factor 15 \\
\hline NM_019232 & 3.82 & 3.14 & Serum/glucocorticoid regulated kinase \\
\hline NM_017073 & 3.81 & 5.20 & Glutamine synthetase 1 \\
\hline NM_012715 & 3.27 & 2.25 & Adrenomedullin \\
\hline NM_053453 & 3.05 & 1.65 & Regulator of G-protein signaling protein 2 \\
\hline NM_022266 & 2.93 & 5.47 & Connective tissue growth factor \\
\hline NM_017277 & 2.93 & 1.00 & Adaptor protein complex AP-1, beta 1 subunit \\
\hline NM_057211 & 2.87 & 3.92 & Kruppel-like factor 9 \\
\hline AI598434 & 2.74 & 6.72 & Endothelial PAS domain protein 1 \\
\hline BM385851 & 2.55 & 2.21 & Period 1 \\
\hline NM_031345 & 2.31 & 4.72 & Glucocorticoid-induced leucine zipper \\
\hline NM_012862 & 2.04 & 3.32 & Matrix Gla protein \\
\hline NM_012894 & 1.64 & 2.86 & Adenosine deaminase, RNA-specific, B1 \\
\hline NM_053796 & 1.39 & 2.58 & Junctional adhesion molecule 1 \\
\hline
\end{tabular}

${ }^{\mathrm{a}}$ Differentiation of rat primary osteoblasts was induced by $\beta$-glycerophosphate and ascorbic acid.

${ }^{b}$ Fold change indicates the alteration of mRNA level in dexamethasone-treated cells over vehicle-treated cells. 
Table 3. Up-Regulated Genes by 2-h or 6-h Treatment with Dexamethasone (10 $\mathrm{nM})$ in Rat Primary Osteoblasts Cultured for 4 Weeks in a Condition of Osteoblastic Differentiation Identified by Microarray Analysis ${ }^{\mathrm{a}}$

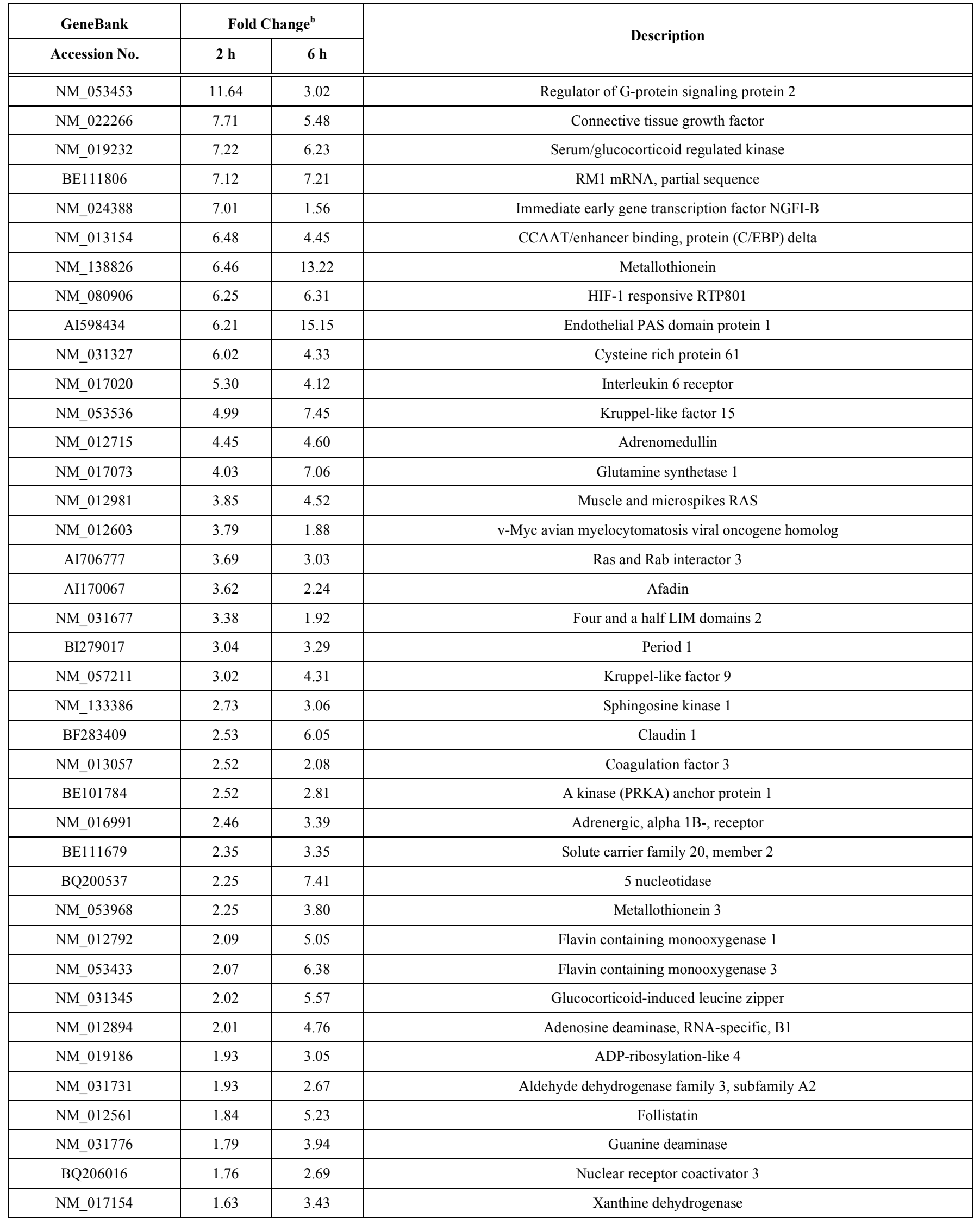


(Table 3) Contd.....

\begin{tabular}{|c|c|c|c|}
\hline \multirow{2}{*}{ GeneBank } & \multicolumn{2}{|c|}{ Fold Change $^{\mathbf{b}}$} & \multirow{2}{*}{ Description } \\
\cline { 1 - 3 } Accession No. & $\mathbf{2 ~ h}$ & $\mathbf{6 ~ h}$ & Cyclin G1 \\
\hline \hline NM_012923 & 1.63 & 3.00 & Matrix Gla protein \\
\hline CB544481 & 1.51 & 2.67 & Platelet derived growth factor receptor, alpha polypeptide \\
\hline AA925099 & 1.38 & 2.73 & Arginase 2 \\
\hline NM_019168 & 1.38 & 2.72 & Cytosolic cysteine dioxygenase 1 \\
\hline NM_052809 & 1.33 & 3.77 & Phospholipase C, beta 4 \\
\hline NM_024353 & 1.29 & 3.14 & Sulfotransferase family 1A, phenol-preferring, member 1 \\
\hline NM_031834 & 1.21 & 2.85 & Osteoclast stimulating factor 1 \\
\hline BQ782951 & 1.19 & 2.60 & Alpha-2-macroglobulin \\
\hline NM_012488 & 1.12 & 2.74 & RAS-like family 11 member B \\
\hline BQ202027 & 1.11 & 3.34 & N-myc downstream-regulated gene 2 \\
\hline NM_133583 & 1.05 & 2.55 & \multirow{2}{*}{} \\
\hline
\end{tabular}

${ }^{a}$ Differentiation of rat primary osteoblasts was induced by $\beta$-glycerophosphate and ascorbic acid.

${ }^{b}$ Fold change indicates the alteration of mRNA level in dexamethasone-treated cells over vehicle-treated cells.

In contrast, 6 and 8 genes were down-regulated by Dex treatment at early and late differentiation stages, respectively (Tables 4 and 5). Three genes were down-regulated at both stages.

\section{Validation of Dex-Induced Up-Regulated Genes Identified in Microarray Analysis}

Among Dex-induced upregulated genes in primary osteoblasts, we were interested in genes that could be related to mesenchymal cell differentiation and bone metabolism. On the basis of these criteria, we identified 4 genes, including $\mathrm{C} / \mathrm{EBP} \delta$, EPAS1, MGP, and NGFI-B. C/EBP $\delta$ is known as a transcriptional activator of adipogenesis similar to other C/EBP family members [18]. EPAS1 is a transcription factor that is also reported to play a role in adipogenic differentiation of 3T3-L1 preadipocytes [19]. MGP is known as a modulator of calcification in osteoblasts [20].
The NR4A family, including NGFI-B, has been shown to regulate osteoblastic gene expression [21,22].

To validate GC-dependent expression of these 4 genes in primary osteoblasts, we performed qPCR using rat primary osteoblasts at early and late differentiation stages treated with 2 different doses of Dex $(10 \mathrm{nM}$ and $1 \mu \mathrm{M})$ (Fig. 1). The upregulated profile of $\mathrm{C} / \mathrm{EBP} \delta$, EPAS1, and MGP mRNA in primary osteoblasts was almost identical at both differentiation periods and at both Dex concentrations. In contrast, the NGFI-B mRNA expression pattern appeared to vary on the basis of the differentiation stage and GC dose. In primary osteoblasts 2 weeks after osteoblastic differentiation, NGFIB mRNA was not induced by the treatment with either Dex dose. In primary osteoblasts 4 weeks after differentiation, NGFI-B mRNA was induced by both Dex doses; upregulation was observed at $2 \mathrm{~h}$ after low-dose treatment and $6 \mathrm{~h}$ after the high-dose treatment.

Table 4. Down-Regulated Genes by 2-h or 6-h Treatment with Dexamethasone (10 nM) in Rat Primary Osteoblasts Cultured for 2 Weeks in a Condition of Osteoblastic Differentiation Identified by Microarray Analysis ${ }^{\mathrm{a}}$

\begin{tabular}{|c|c|c|c|}
\hline GeneBank & \multicolumn{2}{|c|}{ Fold Change $^{\mathbf{b}}$} & \multirow{2}{*}{ Description } \\
\hline \hline Accession No. & $\mathbf{2 ~ h}$ & $\mathbf{6 ~ h}$ & Serum-inducible kinase \\
\hline \hline NM_031821 & 0.23 & 0.13 & Regulator of G-protein signaling 3 \\
\hline NM_019340 & 0.25 & 0.46 & Drosophila polarity gene (frizzled) homologue \\
\hline NM_172035 & 0.58 & 0.24 & Mesenchyme homeo box 2 \\
\hline NM_017149 & 0.96 & 0.27 & Activating transcription factor 3 \\
\hline NM_012912 & 1.15 & 0.28 & Arginine vasopressin receptor 1A \\
\hline NM_053019 & 1.00 & 0.30 & \\
\hline
\end{tabular}

${ }^{\mathrm{a}}$ Differentiation of rat primary osteoblasts was induced by $\beta$-glycerophosphate and ascorbic acid.

${ }^{b}$ Fold change indicates the alteration of mRNA level in dexamethasone-treated cells over vehicle-treated cells. 
Table 5. Down-Regulated Genes by 2-h or 6-h Treatment with Dexamethasone (10 $\mathrm{nM})$ in Rat Primary Osteoblasts Cultured for 4 Weeks in a Condition of Osteoblastic Differentiation Identified by Microarray Analysis ${ }^{\mathrm{a}}$

\begin{tabular}{|l|c|c|c|}
\hline GeneBank & \multicolumn{2}{|c|}{ Fold change $^{\mathbf{b}}$} & Description \\
\cline { 1 - 3 } Accession No. & $\mathbf{2 ~ h}$ & $\mathbf{6 ~ h}$ & Peroxisome proliferator activator receptor, gamma \\
\hline \hline NM_013124 & 0.11 & 0.94 & Regulator of G-protein signaling 3 \\
\hline NM_019340 & 0.17 & 0.42 & Eph receptor A3 \\
\hline NM_031564 & 0.19 & 0.60 & Nuclear receptor subfamily 4, group A, member 3 \\
\hline NM_031628 & 0.23 & 0.21 & Hairy and enhancer of split 1 \\
\hline NM_024360 & 0.26 & 0.80 & Serum-inducible kinase \\
\hline NM_031821 & 0.30 & 0.57 & Drosophila polarity gene (frizzled) homologue \\
\hline NM_172035 & 0.56 & 0.25 & 3-Hydroxy-3-methylglutaryl-Coenzyme A synthase 1 \\
\hline NM_017268 & 0.88 & 0.25 & \\
\hline
\end{tabular}

${ }^{a}$ Differentiation of rat primary osteoblasts was induced by $\beta$-glycerophosphate and ascorbic acid.

${ }^{b}$ Fold change indicates the alteration of mRNA level in dexamethasone-treated cells over vehicle-treated cells.

\section{Stable Expression of EPAS1 Attenuates Induction of Osteoblast Marker Genes during Osteoblastic Differentiation}

Next, we particularly interested in EPAS1 because its remarkable GC-dependent up-regulation was shown at both early and late stage of osteoblastic differentiation, nevertheless, its transcriptional regulatory role in bone has not been well clarified in contrast to its possible promoting function in adipocytic differentiation, as reported in a study using 3T3-L1 preadipocytes [19]. We therefore would like to elucidate whether EPAS1 is a critical transcription factor that modulates osteoblastic differentiation in response to GC treatment. To further characterize the function of EPAS1 during osteoblastic differentiation, we used an in vitro differentiation model of ST2 mouse mesenchymal cells that stably expressed EPAS1 because rat primary osteoblasts were considered to be unsuitable for stable expression of plasmid DNA and appropriate rat-derived undifferentiated osteoblastic cells were not available. It is known that ST2 cells are multipotent and can differentiate into both osteoblast and adipocyte lineages in vitro [23]. We generated ST2 clones that stably expressed human EPAS1 (1-870 amino acids, ST2-EPAS1 cells), a dominant negative mutant of EPAS1 containing the N-terminal domain but lacking the transcriptional activation domain (1-485 amino acids, ST2DN-EPAS1 cells) [24] or the empty vector (ST2-vector cells). Exogenous expression of EPAS1 or DN-EPAS1 was confirmed by qPCR in the ST2-EPAS1 clones E17 and E26 or the ST2-DN-EPAS1 clones D8 and D9, respectively, but not in the ST2-vector clones V1 and V2 (Figs. 2A and B). BMP-9, a recently identified osteoblastic inducer that is more potent than the well-known osteoblastic reagent BMP2 , was used to induce the differentiation of the ST2 clones into the osteoblast lineage $[25,26]$. The expression of the osteoblast marker genes during the differentiation was investigated by qPCR. Overexpression of EPAS1 significantly attenuated the time-dependent induction of ALP and osteocalcin mRNA in ST2-EPAS1 clones on days 6 and 9 compared to the ST2-vector clones (Figs. 2C and D).
Interestingly, ALP and osteocalcin expression was enhanced in the ST2-DN-EPAS1 clones compared with the control clones on days 6 and 9 (Figs. 2C and D). To evaluate the effect of EPAS1 in mineralization, we performed von Kossa staining for these ST2 clones $30 \mathrm{~d}$ after the culture. The intensity of staining was significantly reduced in ST2EPAS1 clones whereas it was enhanced in ST2-DN-EPAS1 clones compared with the ST2-vector clones (Fig. 2E). Taken together, our functional study revealed that EPAS1 negatively modulates the expression of osteoblastic marker genes and functions as an inhibitory factor for osteoblastic differentiation.

\section{DISCUSSION AND CONCLUSION}

In the present study, we identified GC target genes in rat primary osteoblasts at the early and late stages of osteoblastic differentiation by microarray analysis. Among the Dex-induced upregulated genes, we confirmed by qPCR that $\mathrm{C} / \mathrm{EBP} \delta$, EPAS1, and MGP expression was upregulated at both differentiation stages, whereas NGFI-B expression was upregulated only at the late differentiation stage. It is interesting that some of glucocorticoid-induced genes responded to the stimuli in GC dose- and differentiation stagespecific manners because this diversity of GC-induced gene regulation will be related to the various physiological effects of GC in different situations.

Among the GC target genes identified during osteoblastic differentiation, we showed that EPAS1 inhibits osteoblastic differentiation. The stable expression of EPAS1 in ST2 mesenchymal cells reduced the differentiation-dependent induction of osteoblastic marker gene expression, whereas dominant-negative EPAS1 expression substantially enhanced gene induction. EPAS1 is also a transcriptional factor that is shown to play a role in adipocyte differentiation in 3T3-L1 preadipocytic cells during adipogenesis induced by Dex [19]. Taken together, GC modulates mesenchymal cell differentiation by regulating the functions of critical transcriptional factors such as EPAS1. 
A

2-week culture of osteoblastic differentiation

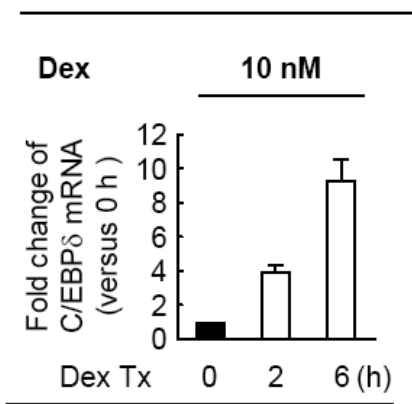

$\begin{array}{lll}\text { Fold change } & 1.06 .845 .19\end{array}$
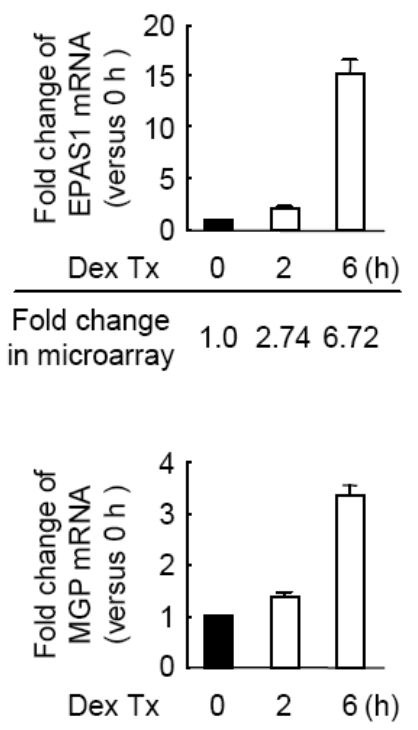

Fold change

in microarray
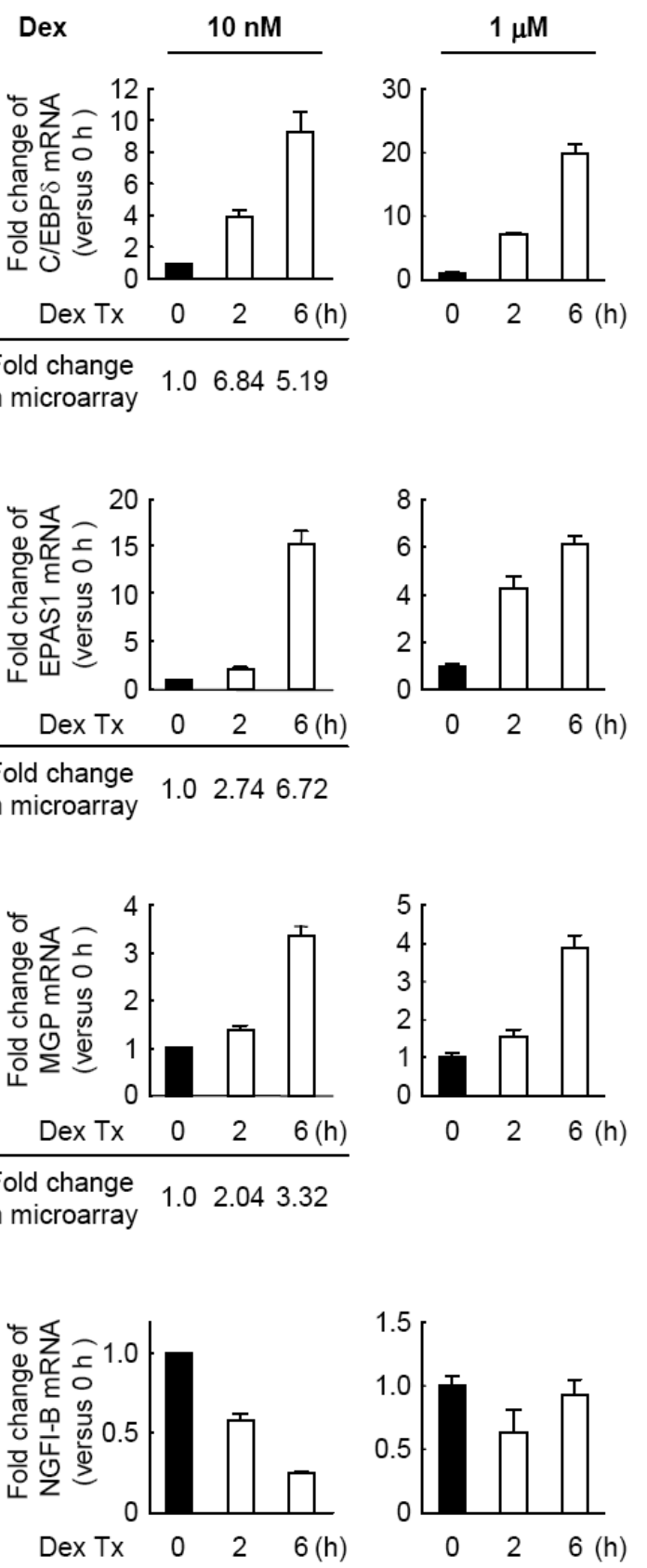

B

4-week culture of osteoblastic differentiation
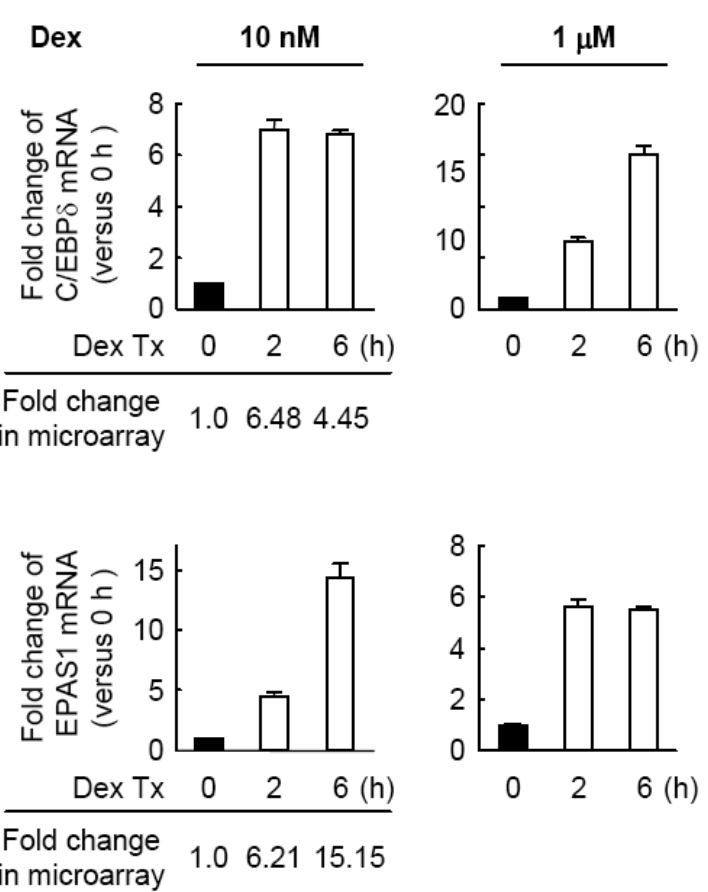
in microarray
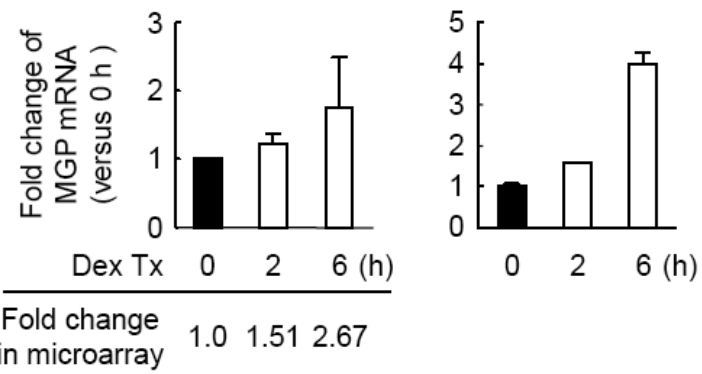

$\begin{array}{llll}\text { Fold change } & 1.0 & 1.512 .67\end{array}$
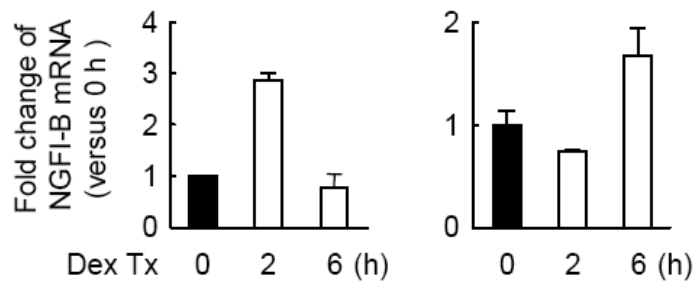

Fold change

in microarray

Fig. (1). Expression of C/EBPS, EPAS1, MGP, and NGFI-B mRNA by Dex treatment in rat primary osteoblasts was analyzed by real-time PCR.

Rat primary osteoblasts were cultured for 2 (A) or 4 (B) weeks, and treated with $10 \mathrm{nM}$ or $1 \mu \mathrm{M}$ Dex. Before and after 2 or $6 \mathrm{~h}$ of treatment, RNA was extracted and the expression levels of the indicated genes were analyzed. The values were normalized to those for GAPDH and shown as the fold change over the mRNA level at $0 \mathrm{~h}$. Each result is the mean \pm SD of 3 independent experiments. The microarray expression values of rat primary osteoblasts treated with $10 \mathrm{nM}$ Dex were shown below of each graph, except NGFI-B data at the time after 2-week culture of osteoblastic differentiation.

We identified the transcriptional factor $\mathrm{C} / \mathrm{EBP} \delta$ as a $\mathrm{GC}$ target in osteoblastic differentiation. It has been also shown that $\mathrm{C} / \mathrm{EBP}$ contributes to adipogenesis like other the $\mathrm{CCAAT} /$ enhancer binding protein family members $\mathrm{C} / \mathrm{EBP} \alpha$ 

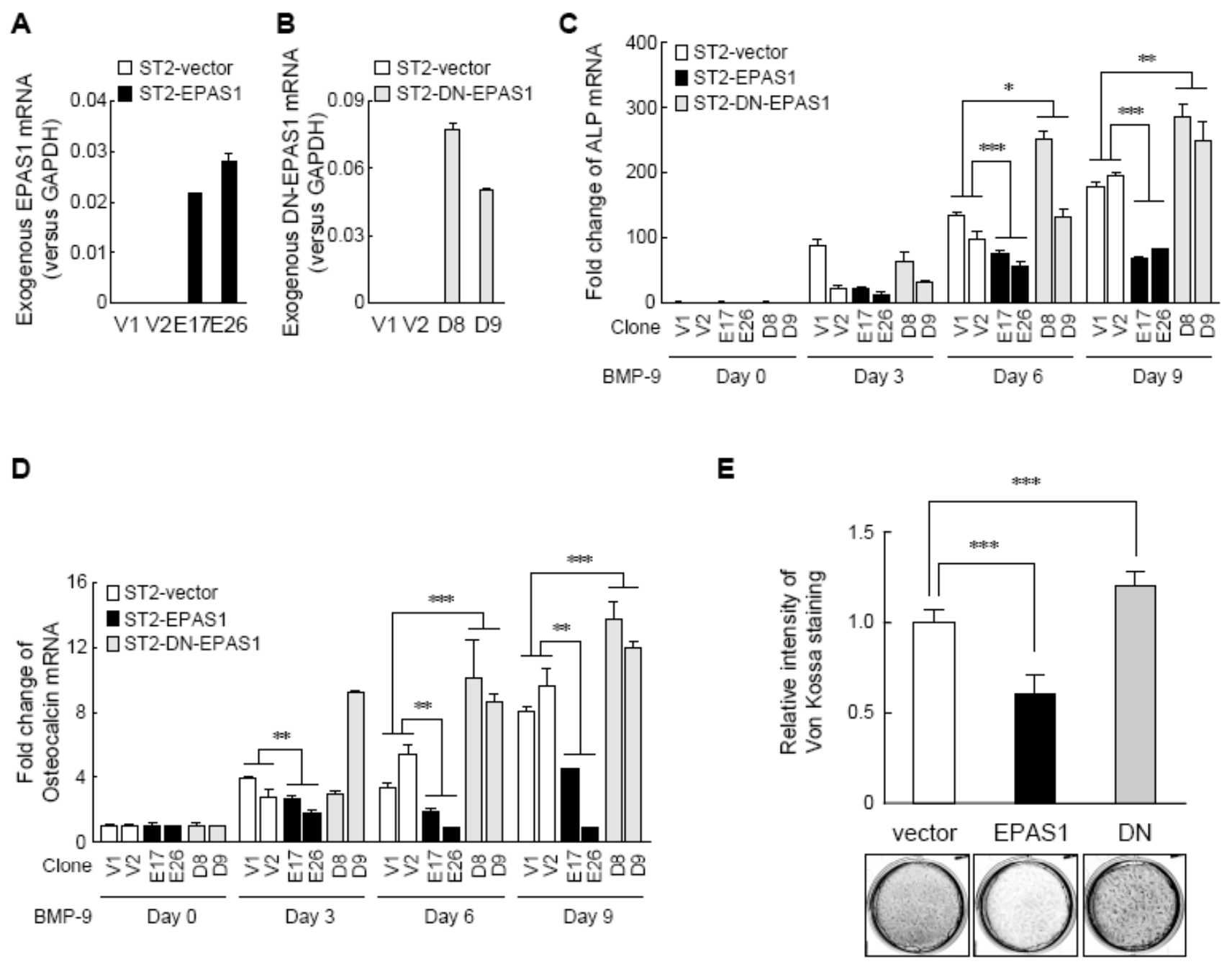

Fig. (2). Stable expression of EPAS1 downregulates osteoblast marker genes during osteoblastic differentiation of ST2 stromal cells.

(A, B) Generation of ST2 cells that stably express EPAS1 (ST2-EPAS1) or dominant negative EPAS1 mutants (ST2-DN-EPAS1). Control vector-expressing clones (V1 and V2), EPAS1-expressing clones (E17 and E26), and DN-EPAS1 clones (D8 and D9) were isolated by G418 selection. Expression of exogenous EPAS1 or DN-EPAS1 mRNA in ST2 clones were validated by qPCR. (C and D) mRNA levels of ALP (C) and osteocalcin (D) in each clone during osteoblastic differentiation treated with BMP-9 (20 ng/ml) at indicated time points were examined by qPCR. Results are shown as the fold change in the mRNA expression level in each clone at day 0 . Each result is the mean $\pm \mathrm{SD}$ of 3 independent experiments. ${ }^{*}, \mathrm{p}<0.05 ; * *, \mathrm{p}<0.01{ }^{* * *}, \mathrm{p}<0.001$ (Student's $t$ test). (E) von Kossa staining of ST-EPAS1 or ST2-DNEPAS1 cells after $30 \mathrm{~d}$ of osteoblastic differentiation. Results represent the mean \pm SD of the relative intensity in 6 independent areas. ***, $p$ $<0.001$ (by Student's $t$ test).

and $\mathrm{C} / \mathrm{EBP} \beta[18,27]$. In primary osteoblasts, $\mathrm{C} / \mathrm{EBP} \delta$ is reported to play a role in $\mathrm{GC}$-dependent transcriptional repression of insulin-like growth factor (IGF)-I [28]. Since IGF$\mathrm{I}$ is a known regulator of bone acquisition and maintenance [29], our results of GC-dependent $\mathrm{C} / \mathrm{EBP} \delta$ upregulation in osteoblastic differentiation suggest that $\mathrm{GC}$ represses some essential osteoblastic signals, such as IGF-I, via $\mathrm{C} / \mathrm{EBP} \delta$ dependent transcriptional regulation.

GC-dependent upregulation of MGP is another critical factor that contributes to the suppression of osteoblastic differentiation and bone acquisition. MGP is one of the noncollagenous bone matrix proteins. In addition to our findings, GC-dependent MGP upregulation has also been reported in rat lung cells [30]. A previous study of MGP knockout mice suggests that MGP is an inhibitor of bone mineralization, as MGP-deficient mice exhibit inappropriate calcification of various cartilages and ectopic vascular calcification [20]. Therefore, GC-dependent upregulation of MGP could also play a role in the inhibition of bone formation by suppressing mineralization in vivo.

Compared with other GC target genes that we focused on in the present study, the NGFI-B mRNA expression pattern seems to vary on the basis of the differentiation stage and Dex concentration. NGFI-B, also known as Nur77 or TR3, is a nuclear orphan receptor that belongs to the NR4A subfamily [31]. NGFI-B expression is induced by phytohemagglutinin in human lymphocytes and by serum stimulation of arrested fibroblasts [32]. Translocation of the NGFI-B 
protein from the nucleus to mitochondria induces apoptosis [33]. Regarding the relationship between NR4A and bone formation, the NR4A family has been shown to regulate osteoblastic gene expression [34]. Our RT-PCR results show that the regulation of NGFI-B expression by Dex in primary osteoblasts was dependent on both the dose and differentiation stage. These results were consistent with the microarray data as NGBI-B mRNA was found to be upregulated in a Dex-dependent manner only in primary osteoblasts at 4 weeks after osteoblastic differentiation. However, we could not rule out the possibility that NGFI-B expression may be up-regulated within $2 \mathrm{~h}$, therefore, it is necessary to examine whether the acute change of NGFI-B expression may occur. On the other hand, C/EBP $\delta$, EPAS1, and MGP were found to be upregulated in a Dex-dependent manner in primary osteoblasts at both differentiation stages, suggesting that some of glucocorticoid-induced genes respond to the stimuli in GC dose- and differentiation stage-specific manners.

In conclusion, we revealed in the present study that $\mathrm{C} / \mathrm{EBP} \delta$, EPAS1, MGP, and NGFI-B were upregulated by Dex. EPAS1 overexpression inhibited, while dominant-negative EPAS1 overexpression enhanced the upregulation of osteoblastic marker genes and the mineralization in ST2 mesenchymal cells during osteoblastogenesis. We propose that glucocorticoids inhibit osteoblastic differentiation by regulating target genes such as EPAS1.

\section{ABBREVIATIONS}

$$
\begin{aligned}
& \text { Dex } \\
& \text { BMP-9 }=\text { Dexamethasone } \\
& \text { FBS }=\text { Fetal bovine serum } \\
& \text { GAPDH }=\text { Glyceraldehyde-3-phosphate dehydrogenase } \\
& \text { ALP }=\text { Alkaline phosphatase } \\
& \text { C/EBP }=\text { CCAAT enhancer binding protein delta } \\
& \text { EPAS1 }=\text { Endothelial PAS domain protein } 1 \\
& \text { MGP }=\text { Matrix gla protein } \\
& \text { NGFI-B }=\text { Nerve growth factor induced protein I-B } \\
& \text { qPCR }=\text { Quantitative reverse transcriptase-polymerase }
\end{aligned}
$$

\section{ACKNOWLEDGEMENTS}

We thank Dr. Katagiri (Saitama Medical University) for technical advice. We are also grateful to Ms. M. Kumasaka, E. Sekine, and W. Satoh for expert technical assistance. This work was supported in part by grants-in-aid from the Ministry of Health, Labor and Welfare, from the Japan Society for the Promotion of Science, and a grant of the Genome Network Project and 'DECODE' from the Ministry of Education, Culture, Sports, Science and Technology of Japan.

\section{REFERENCES}

[1] Canalis E, Delany AM. Mechanisms of glucocorticoid action in bone. Ann N Y Acad Sci 2002; 966: 73-81.
[2] Delany AM, Dong Y, Canalis E. Mechanisms of glucocorticoid action in bone cells. J Cell Biochem 1994; 56: 295-302.

[3] Weinstein RS, Jilka RL, Parfitt AM, Manolagas SC. Inhibition of osteoblastogenesis and promotion of apoptosis of osteoblasts and osteocytes by glucocorticoids. Potential mechanisms of their deleterious effects on bone. J Clin Invest 1998; 102: 274-82.

[4] Hara K, Akiyama Y, Ohkawa I, Tajima T. Effects of menatetrenone on prednisolone-induced bone loss in rats. Bone 1993; 14: 813-8.

[5] Centrella M, McCarthy TL, Canalis E. Glucocorticoid regulation of transforming growth factor $\beta 1$ activity and binding in osteoblastenriched cultures from fetal rat bone. Mol Cell Biol 1991; 11: 4490-6.

[6] Delany AM, Gabbitas BY, Canalis E. Cortisol downregulates osteoblast $\alpha 1$ (I) procollagen mRNA by transcriptional and posttranscriptional mechanisms. J Cell Biochem 1995; 57: 488-94.

[7] Chang DJ, Ji C, Kim KK, Casinghino S, McCarthy TL, Centrella $\mathrm{M}$. Reduction in transforming growth factor $\beta$ receptor I expression and transcription factor $\mathrm{CBFa} 1$ on bone cells by glucocorticoid. J Biol Chem 1998; 273: 4892-6.

[8] Gohel A, McCarthy MB, Gronowicz G. Estrogen prevents glucocorticoid-induced apoptosis in osteoblasts in vivo and in vitro. Endocrinology 1999; 140: 5339-47.

[9] Smith E, Redman RA, Logg CR, Coetzee GA, Kasahara N, Frenkel B. Glucocorticoids inhibit developmental stage-specific osteoblast cell cycle. Dissociation of cyclin A-cyclin-dependent kinase 2 from E2F4-p130 complexes. J Biol Chem 2000; 275: 19992-20001.

[10] Pereira RM, Delany AM, Canalis E. Cortisol inhibits the differentiation and apoptosis of osteoblasts in culture. Bone 2001, 28: 484-90

[11] Bellows CG, Aubin JE, Heersche JN. Physiological concentrations of glucocorticoids stimulate formation of bone nodules from isolated rat calvaria cells in vitro. Endocrinology 1987; 121: 198592.

[12] Ogata Y, Yamauchi M, Kim RH, Li JJ, Freedman LP, Sodek J. Glucocorticoid regulation of bone sialoprotein (BSP) gene expression. Identification of a glucocorticoid response element in the bone sialoprotein gene promoter. Eur J Biochem 1995; 230: 183-92.

[13] Olkku A, Bodine PV, Linnala-Kankkunen A, Mahonen A. Glucocorticoids induce glutamine synthetase expression in human osteoblastic cells: a novel observation in bone. Bone 2004; 34 : 3209 .

[14] Ohnaka K, Taniguchi H, Kawate H, Nawata H, Takayanagi R. Glucocorticoid enhances the expression of dickkopf-1 in human osteoblasts: novel mechanism of glucocorticoid-induced osteoporosis. Biochem Biophys Res Commun 2004; 318: 259-64.

[15] Urano $\mathrm{T}$, Yashiroda $\mathrm{H}$, Muraoka $\mathrm{M}$, et al. $\mathrm{p} 57^{\mathrm{Kip} 2}$ is degraded through the proteasome in osteoblasts stimulated to proliferation by transforming growth factor $\beta 1$. J Biol Chem 1999; 274: 12197-200.

[16] Horie-Inoue K, Takayama K, Bono HU, Ouchi Y, Okazaki Y, Inoue $\mathrm{S}$. Idnetification of bioinformatics and functional analysis of hormone response elements. Biochem Biophys Res Commun 2006; 339: 99-106.

[17] Otsuka E, Yamaguchi A, Hirose S, Hagiwara H. Characterization of osteoblastic differentiation of stromal cell line ST2 that is induced by ascorbic acid. Am J Physiol 1999; 277: C132-8.

[18] Tanaka T, Yoshida N, Kishimoto T, Akira S. Defective adipocyte differentiation in mice lacking the $\mathrm{C} / \mathrm{EBP} \beta$ and/or $\mathrm{C} / \mathrm{EBP} \delta$ gene. EMBO J 1997; 16: 7432-43

[19] Shimba S, Wada T, Hara S, Tezuka M. EPAS1 promotes adipose differentiation in 3T3-L1 cells. J Biol Chem 2004; 279: 40946-53

[20] Luo G, Ducy P, McKee MD, et al. Spontaneous calcification of arteries and cartilage in mice lacking matrix GLA protein. Nature 1997; 386: 78-81.

[21] Tetradis S, Bezouglaia O, Tsingotjidou A, Vila A. Regulation of the nuclear orphan receptor Nur77 in bone by parathyroid hormone. Biochem Biophys Res Commun 2001; 281: 913-6.

[22] Pirih FQ, Tang A, Ozkurt IC, Nervina JM, Tetradis S. Nuclear orphan receptor Nurrl directly transactivates the osteocalcin gene in osteoblasts. J Biol Chem 2004; 279: 53167-74.

[23] Ding J, Nagai K, Woo JT. Insulin-dependent adipogenesis in stromal ST2 cells derived from murine bone marrow. Biosci Biotechnol Biochem 2003; 67: 314-21.

[24] Maemura K, Hsieh CM, Jain MK, et al. Generation of a dominantnegative mutant of endothelial PAS domain protein 1 by deletion of 
a potent C-terminal transactivation domain. J Cell Biochem 1999; 274: 31565-70.

[25] Dayoub H, Dumont RJ, Li JZ, et al. Human mesenchymal stem cells transduced with recombinant bone morphogenetic protein- 9 adenovirus promote osteogenesis in rodents. Tissue Eng 2003; 9: 347-56.

[26] Kang Q, Sun MH, Cheng H, et al. Characterization of the distinct orthotopic bone-forming activity of 14 BMPs using recombinant adenovirus-mediated gene delivery. Gene Ther 2004; 11: 1312-20.

[27] Darlington GJ, Ross SE, MacDougald OA. The role of C/EBP genes in adipocyte differentiation. J Biol Chem 1998; 273: 3005760.

[28] Delany AM, Durant D, Canalis E. Glucocorticoid suppression of IGF I transcription in osteoblasts. Mol Endocrinol 2001; 15: 17819.

[29] Holmes SJ, Shalet SM. Role of growth hormone and sex steroids in achieving and maintaining normal bone mass. Horm Res 1996; 45: 86-93.
[30] Gilbert KA, Rannels SR. Glucocorticoid effects on vitamin Kdependent carboxylase activity and matrix Gla protein expression in rat lung. Am J Physiol Lung Cell Mol Physiol. 2003; 285: L56977.

[31] Chang C, Kokontis J, Liao SS, Chang Y. Isolation and characterization of human TR3 receptor: a member of steroid receptor superfamily. J Steroid Biochem 1989; 34: 391-5.

[32] Nakai A, Kartha S, Sakurai A, Toback FG, DeGroot LJ. A human early response gene homologous to murine nur77 and rat NGFI-B, and related to the nuclear receptor superfamily. Mol Endocrinol 1990; 4: 1438-43.

[33] Lin B, Kolluri SK, Lin F, et al. Conversion of Bcl-2 from protector to killer by interaction with nuclear orphan receptor, Nur77/TR3. Cell 2004; 116: 527-40.

[34] Martens C, Bilodeau S, Maira M, Gauthier Y, Drouin J. Proteinprotein interactions and transcriptional antagonism between the subfamily of NGFI-B/Nur77 orphan nuclear receptors and glucocorticoid receptor. Mol Endocrinol 2005; 19: 885-97.

Received: March 24, 2009

(C) Ijichi et al.; Licensee Bentham Open.

This is an open access article licensed under the terms of the Creative Commons Attribution Non-Commercial License (http://creativecommons.org/licenses/by$\mathrm{nc} / 3.0 /$ ), which permits unrestricted, non-commercial use, distribution and reproduction in any medium, provided the work is properly cited. 